\title{
CYSTIC ADVENTITIAL DISEASE OF THE POPLITEAL ARTERY: REPORT ON THREE CASES AND REVIEW OF THE LITERATURE
}

\author{
Petr Drac ${ }^{a *}$, Martin Köcher ${ }^{\mathrm{b}}$, Petr Utikal ${ }^{\mathrm{a}}$, Marie Cerna ${ }^{\mathrm{b}}$, Jiri Kozak ${ }^{\mathrm{b}}$, Petr Bachleda ${ }^{\mathrm{a}}$
}

\author{
${ }^{a}$ Department of Surgery II - Vascular and Transplantation Surgery, University Hospital Olomouc, Czech Republic \\ ${ }^{b}$ Clinic of Radiology, University Hospital Olomouc \\ E-mail:petr.drac@fnol.cz
}

Received: May 6, 2011; Accepted with revision: November 22, 2011; Available online: December 19, 2011

Key words: Cystic adventitial disease/Popliteal artery/Etiology/Diagnostics/Treatment

Background. During the past nine years three cases of cystic adventitial disease of the popliteal artery have been diagnosed and treated in our medical institution. Different approaches were used in the treatment in all these cases. The purpose of this report is to summarise the current knowledge of the etiology, presentation, diagnostics and treatment of this condition, with the addition of new cases.

Methods. Information about three new cases is presented and discussed together with that from the relevant publications obtained from the Pubmed database.

Results. In the first case resection with synthetic graft interposition was used. Nine years after the surgery the patient is without any signs of recurrence, but he experienced local thrombolysis of the occluded graft and repeated PTA of hemodynamically significant anastomotic stenoses. The second case treated with US-guided aspiration has demanded repeated reinterventions due to recurrence; nevertheless, the result is satisfactory. In the last instance, the cyst was evacuated and excised. Six months after the surgery the patient is symptom-free and without signs of recurrence.

Conclusions. CAD of the popliteal artery is a rare vascular condition. However, it must be considered in the differential diagnosis, especially in middle-aged male patients without evidence of atherosclerotic disease in whom intermittent claudication has developed suddenly with a rapid progression or with fluctuation in severity. Duplex ultrasound and MRA are the the best diagnostic methods. Based on the existing knowledge, the treatment of choice is surgery (either evacuation with the removal of the cystic wall or resection and grafting).

\section{INTRODUCTION}

Cystic adventitial disease is a rare vascular condition that causes localised stenosis or occlusion. The cysts are unilocular or multilocular, contain mucin and are situated within the adventitia. Damage to the media and intima, if present, is considered to be secondary ${ }^{1}$ but a rare case of severe mucoid degeneration of the intima and media has also been described ${ }^{2}$. The condition is predominantly located in the popliteal artery (approximately 85 per cent of cases) but other investigators have reported involvement of the external iliac ${ }^{3,4}$, common femoral ${ }^{5-8}$, axillary ${ }^{9}$, distal brachial $^{2}$, radial and ulnar arteries ${ }^{10,11}$. Veins can also be affected, e.g. the common femoral, popliteal or the great saphenous vein of the ankle $\mathrm{e}^{12-14}$, but the number of cases is 20 times lower than that associated with arteries ${ }^{15}$. CAD is most common in male subjects, with a male-to-female ratio of $5: 1$. It usually manifests in the $4^{\text {th }}$ or $5^{\text {th }}$ decade of life and is mostly unilateral even though a few cases of bilateral involvement ${ }^{16,17}$ and of the occurrence in very young ${ }^{18-20}$ and old patients ${ }^{21,22}$ have also been reported. The patients are often otherwise healthy, without signs of atherosclerotic disease or cardiovascular risk factors, and some are active sportsmen ${ }^{15,16,23-28}$. Most reported cases are from Europe and Japan ${ }^{24}$. The incidence of CAD is estimated to be in 1200 cases of claudication. This disease was first described in 1947 by Atkins and $\mathrm{Key}^{3}$, in a patient with CAD that affected the external iliac artery. The etiology of CAD remains controversial.

Several techniques have been used for CAD investigation and treatment. This review summarises these different methods and presents the data supporting the current consensus. In addition, we present three new cases of popliteal artery CAD.

\section{CLINICAL EXAMPLE}

Case 1. A 46 year old man was investigated for cramplike pain in the popliteal fossa and in the right calf, mainly in the knee flexion - during walking and in the squatting position, with the pain lasting over one year. He also observed the peripherals of the leg turning pale in such situations. The intermittent claudication was disabling, and the recovery time after the cessation of walking was sometimes as much as $15 \mathrm{~min}$. No vascular risk factors were reported except hypertension. There was no history of trauma or extreme sports and the patient had always worked only in an office. The lower extremities revealed no evidence of ischemia and all the palpable pulses except the dorsalis pedis on the right side were present, but palpable resistance was noted in the right popliteal fossa. The first sonographist performing duplex ultrasound described a small popliteal artery aneurysm with a mural 


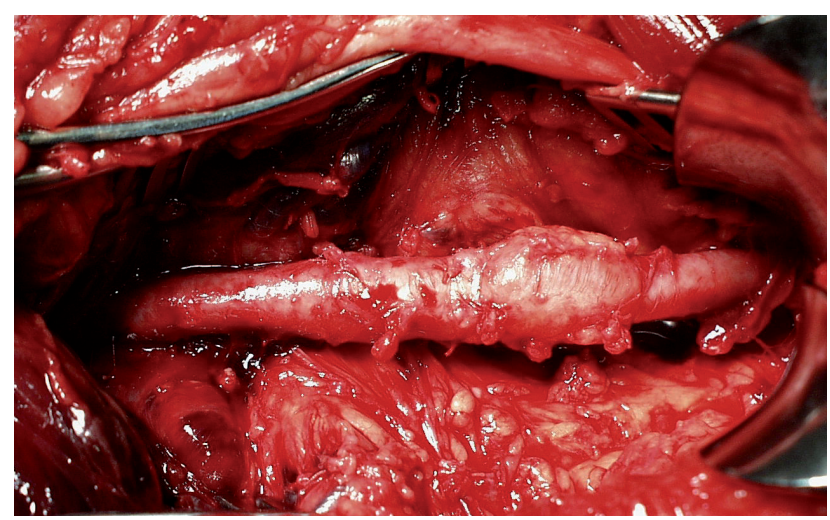

Fig. 1. Case 1: Peroperative view - popliteal artery with adventitial cyst.

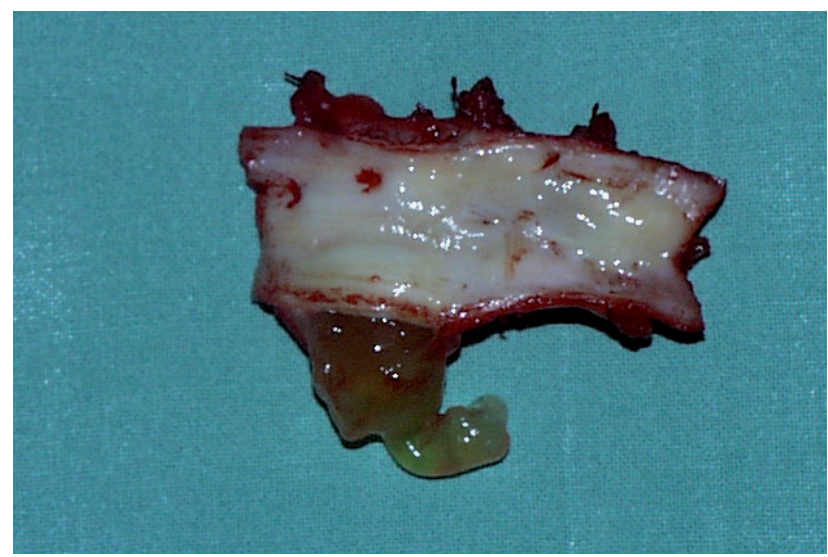

Fig. 2. Case 1: Peroperative view - resected part of popliteal artery with gelatinous content escaping from the adventitial cyst.

thrombus. Another sonographist did not prove the popliteal artery aneurysm or the stenosis of the artery, but he also did not discover an adventitial cyst. DSA did not demonstrate a stenosis or aneurysm of the right popliteal artery, and showed in the calf dominant fibular artery filling plantar artery. No other significant pathology was found in the arteries of both lower extremities. Clinical check-up was planned 6 weeks later, but the patient arrived 3 months after the examination with an acute condition of $3 \mathrm{~h}$ ischemia of the right lower extremity. The condition involved the loss of peripheral pulsation but the limb was not in immediate danger. The sonographist then described the dissection of the popliteal artery with a thrombosed false lumen which critically stenosed the true lumen. MRA was not performed at our centre as a standard at the time, for which reason CTA was indicated. The method did not confirm the dissection and again assessed the condition as a small aneurysm of the popliteal artery with a wall thrombus significantly stenosing the lumen of the artery. It was noted on that occasion that the hypodense soft-tissue structure was most likely a thrombus. The outflow bedside was the same as when compared to the previous DSA. Only by means of surgery via an S-shaped posterior incision over the popliteal fossa was it demonstrated that the arterial wall contained cysts

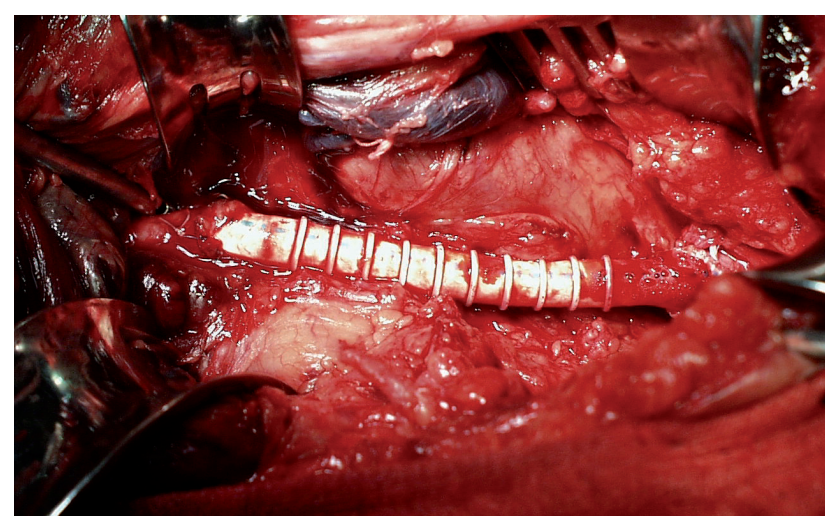

Fig. 3. Case 1: Peroperative view - popliteal artery replaced with ePTFE ring interposition.

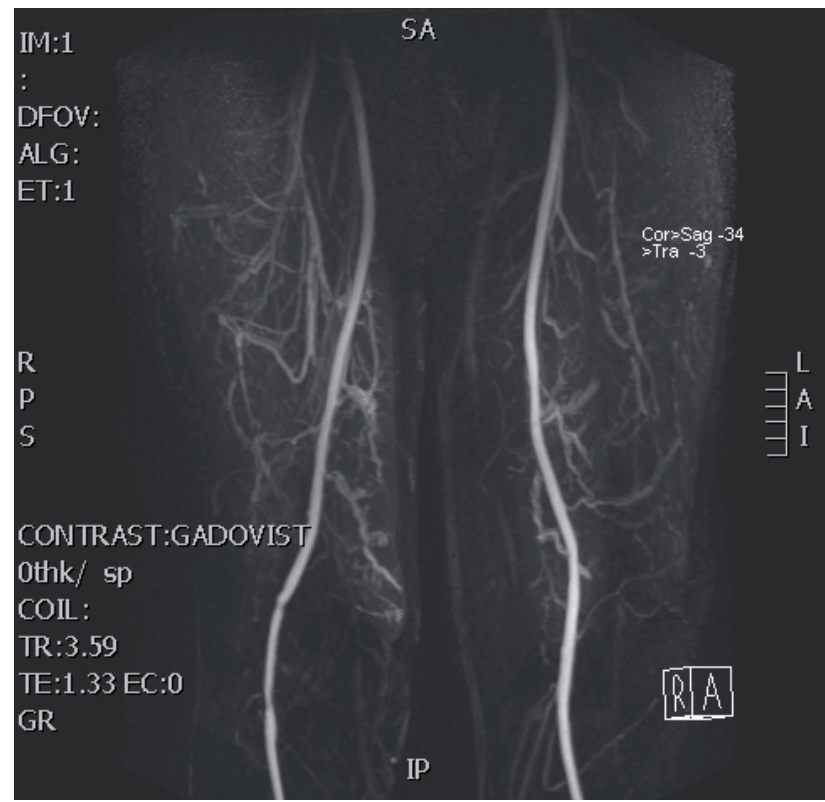

Fig. 4. Case 1: Postoperative magnetic resonance angiography - status after popliteal artery replacement, borderly significant restenoses in both anastomoses.

N.B. the records of preoperative investigations have not beeen preserved

and that the condition involved was therefore CAD. No connection of the cyst to the knee joint was observed. The affected popliteal artery portion was resected and a $6 \mathrm{~mm}$ ePTFE ring graft (Gore, Inc) was interposed. The patient's postoperative course was free of complications; the pulse on the posterior tibial artery reappeared, aspirin at a dose of $100 \mathrm{mg}$ daily was recommended to him and he was discharged 11 days after the surgery. The histologic examination of the resected popliteal artery revealed both the cystic degeneration of the adventitia and Erdheim's cystic medionecrosis and atherosclerosis. Acid mucopolysaccharides were found in the adventitial cysts. Five months later the patient experienced the recurrence of acute right lower limb ischemia. Disabling intermittent claudication was the only clinical manifestation. Duplex ultrasound revealed, and DSA confirmed the occlusion of the ePTFE interposition. Local thrombolysis was chosen 
to restore graft patency, and was successful. PTA was used for the dilatation of the stenoses of both the anastomoses with suboptimal technical success. The posterior tibial artery pulse reappeared. The patient received oral anticoagulant therapy instead of antiplatelet one. However, he ceased to tolerate the therapy after approximately 5 years and antiplatelet treatment was reintroduced, with clopidogrel administered at the daily dose of $75 \mathrm{mg}$. The patient was symptom-free, without claudication. Only approximately two and a half years after the previous intervention, he observed momentary ischemia of the big toe on his right foot, with suspected digital embolisation. MRA demonstrated a patent graft with a borderline significant restenosis in both anastomoses, and no signs of CAD recurrence. Another 3 years later, the claudication recurred. The patient failed to complete MRA because of nausea. The antegrade DSA of the right lower limb was performed directly and the previously demonstrated and then-already haemodynamically significant restenoses of the two anastomoses were dilated with PTA with technical success. Claudication reoccurred another 18 months later, restricting the patient's ability to walk further than 300 metres. The patient agreed with investigation using CTA, which demonstrated the further restenosis of the two anastomoses - borderline proximal and very significant distal ones. The PTA was again technically successful. No signs of CAD recurrence or CAD occurrence on the other limb were found. Nine years after the surgery the patient is nearly symptom free (intermittent claudication in the right calf after more than one kilometre of walking), with a palpable pedal pulse on the right lower limb and no sign of recurrence on duplex ultrasound.

Case 2. A 54 year old man presented with an approximately three-week history of intermittent claudication in the left calf with a symptom-free walk interval of 50-100 metres without rest pain. The recovery time after the cessation of walking was approximately one to two minutes. He worked as a fitter and furnace service technician in a steel plant. His medical history included impaired glucose tolerance and glaucoma. He used to be a competitive runner when was younger, had suffered a right ankle fracture, and had been a non-smoker for 11 years. No other cardiovascular risk factors, history of other trauma or prior surgical history were revealed. He was referred to our vascular surgery out patient department by a physician as a result of a performed duplex ultrasound examination. A partially thrombosed aneurysm of the popliteal artery with residual lumen corresponding to haemodynamically significant stenosis was diagnosed. Upon examination, there was no evidence of acute ischemia, all of our patient's lower limb pulses were palpable, and no resistance was palpable in his popliteal fossas. The patient was referred for DSA, which suspected CAD - a smooth, eccentric, haemodynamically significant stenosis of the proximal part of the left popliteal artery was revealed. Otherwise the findings regarding his lower limb arteries were negative. The diagnosis was confirmed with MRA, which, in addition to the above-mentioned stenosis, also demonstrated a cyst in the arterial wall, $33 \mathrm{~mm}$ in length and $10 \mathrm{~mm}$ in di-

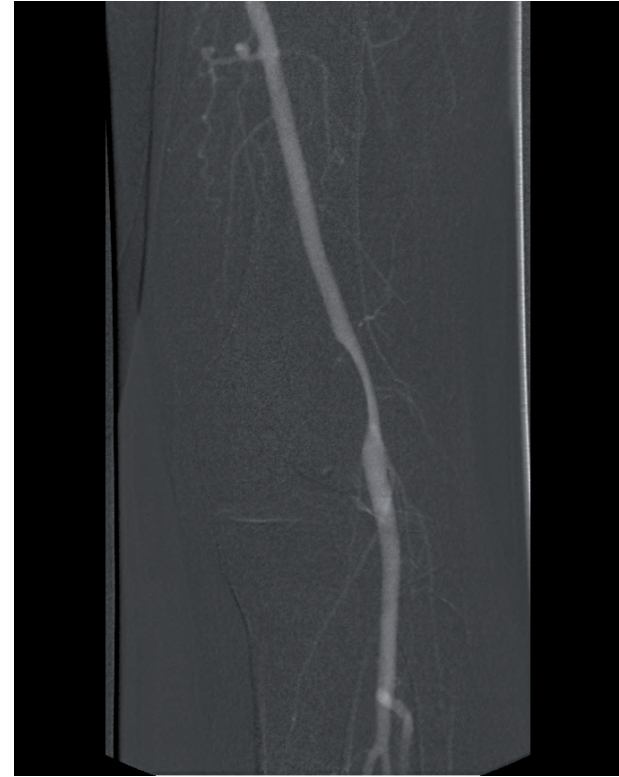

Fig. 5. Case 2: Digital subtraction angiography - scimitar sign.

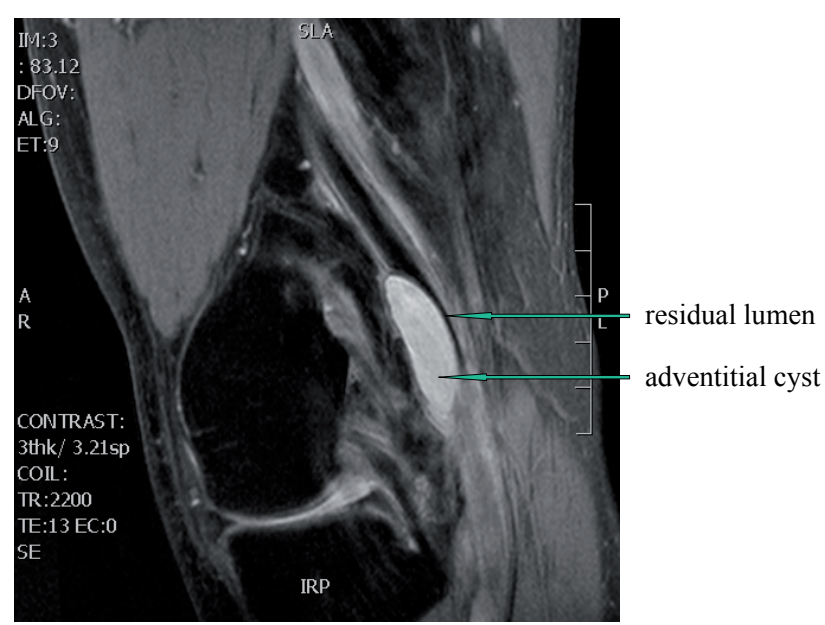

Fig. 6. Case 2: Magnetic resonance angiography, sagital scan - popliteal artery with adventitial cyst.

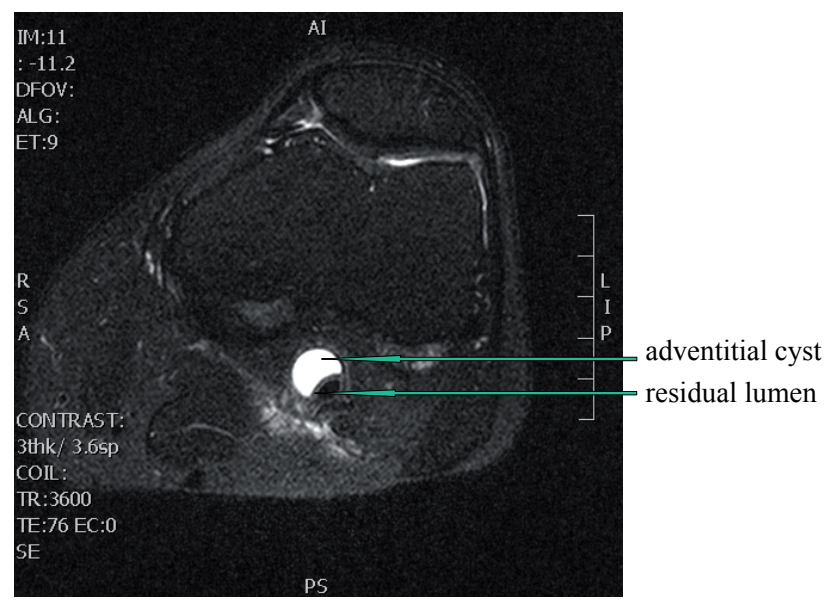

Fig. 7. Case 2: Magnetic resonance angiography, transversal scan - popliteal artery with advetitial cyst. 


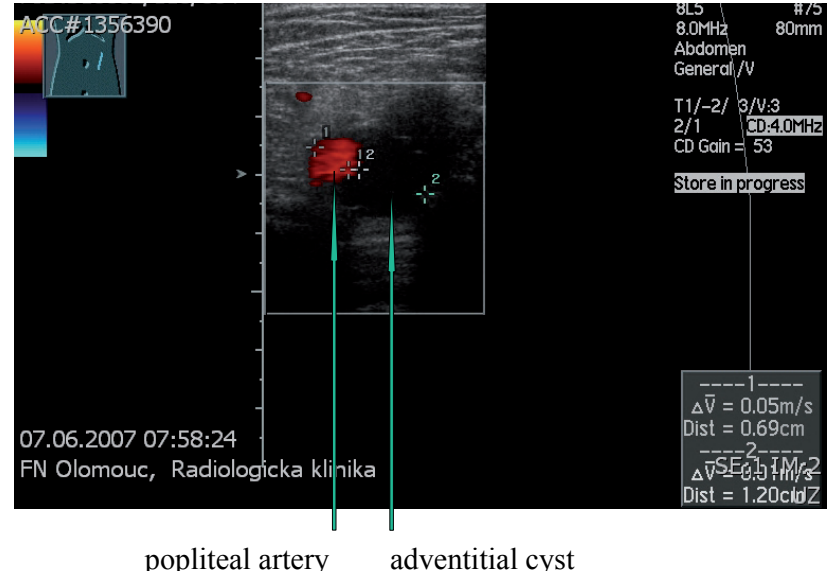

Fig. 8. Case 2: Duplex ultrasound - popliteal artery with advetitial cyst.

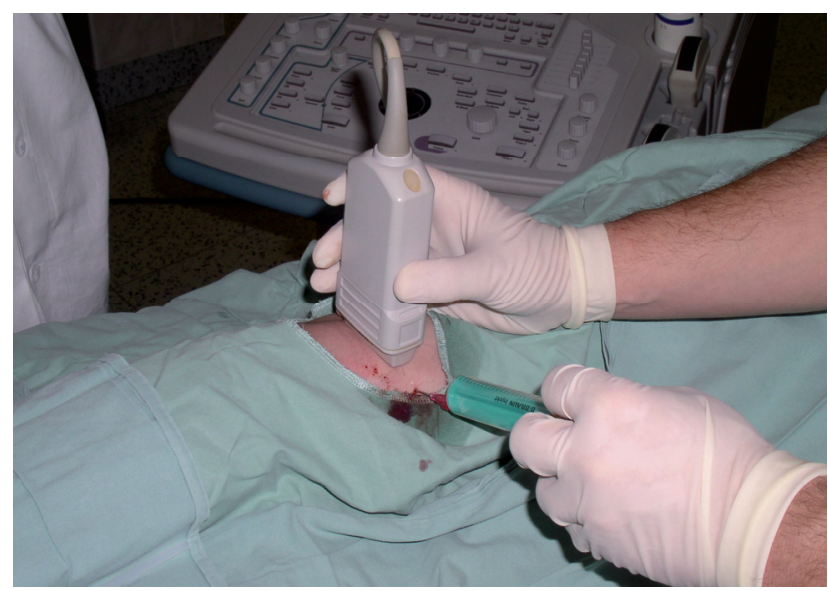

Fig. 9. Case 2: Periprocedural view - US - guided percutaneous cyst aspiration.

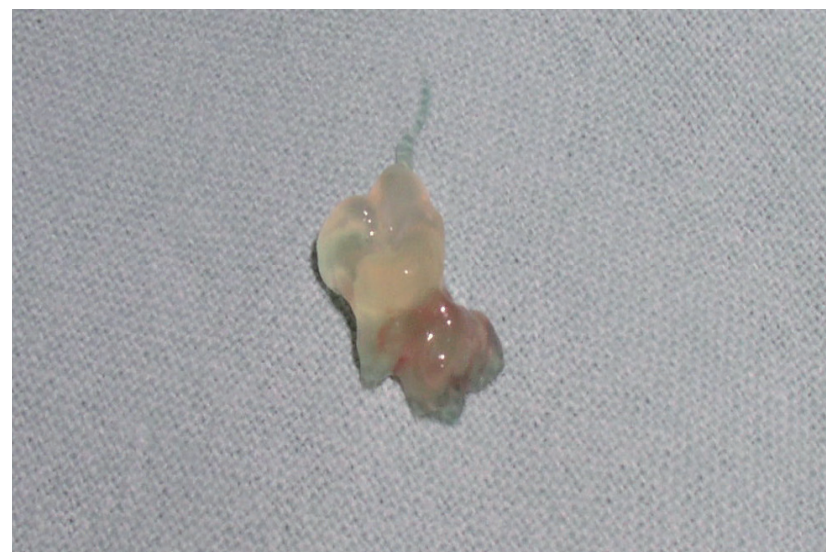

Fig. 10. Case 2: Periprocedural view - the content obtained from US - guided percutaneous cyst aspiration.

ameter. No communication to the knee joint was visible. Interestingly, it also showed the accidental finding of an asymptomatic Baker's cyst in the right popliteal fossa, but the right popliteal artery was intact. The patient was not inclined towards open surgery but agreed with the less invasive US-guided percutaneous cyst aspiration. First, an unsuccessful aspiration attempt was performed with the $21-\mathrm{G}$ needle. Then the needle was replaced with a $16-\mathrm{G}$ one and $2 \mathrm{ml}$ of mucinous cystic content was evacuated. Local anaesthesia was used. Even though the complete evacuation of the cyst was not achieved, the stenosis disappeared, as did the patient's complaints. Antiplatelet therapy was introduced, specifically, a dose of $100 \mathrm{mg}$ of aspirin per day. His intermittent calf claudication recurred three months later but with a longer symptom-free walk interval - 300 metres. Duplex ultrasound confirmed the replenishment of the cyst approximately up to its original size. It again caused haemodynamically significant stenosis. Using a $16-\mathrm{G}$ needle, $3 \mathrm{ml}$ of cystic content was evacuated, leading to a nearly complete cyst evacuation and disappearance of the stenosis. The patient remained asymptomatic for another 5 months, which was again followed by intermittent calf claudication after 300 metres. Even before that, i.e. 4 months after the second aspiration, follow-up duplex ultrasound demonstrated the partial replenishment of the cyst resulting in haemodynamically insignificant stenosis. The patient decided to undergo the third US-guided aspiration another 3 months later, when the symptom-free walk interval shortened to 150 metres. Duplex ultrasound performed at the time again showed a cyst of approximately the original size which significantly stenosed the arterial lumen. $5 \mathrm{ml}$ was evacuated with a residual cyst of $30 \times 6 \mathrm{~mm}$ but without significant stenosis. Claudication recurred another 4 months later, involving a symptom-free walk interval of 100 metres. According to duplex ultrasound examination, the cyst had progressed to reach a larger size than the original one $-40 \times 12 \mathrm{~mm}$. Aspiration led to the nearly complete evacuation of the cyst and to the normalisation of the blood flow. The patient was asymptomatic for approximately one year. Even though duplex ultrasound showed the replenishment of the cyst up to the size of $40 \mathrm{~mm}$ in length and approximately $15 \mathrm{~mm}$ in width, no stenosis of the popliteal artery was found (during the investigation usually performed at rest and with the extremity extended). A slight progression subsequently occurred towards non-limiting complaints, and this condition has lasted for three and a half years and is stabilised. It involves mild calf claudications after 200 metres of walking. The sensation perceived is pressure rather than pain and it is demonstrated mainly when walking uphill. The patient is not forced to stop and only needs to slow down, and he is almost symptom-free when walking on a flat surface. The dopplerometric examinations performed during the period showed that the size of the cyst was first rather stable but began to reduce gradually to $20 \times 2 \mathrm{~mm}$ and then fully disappeared, which was also confirmed by MRA, which was completely negative. The left popliteal artery showed no cyst or stenosis while no CAD signs and a continued regression of the Baker's cyst were found on the other, asymptomatic limb. During the period, the patient checked in once, complaining of approximately two weeks of pain on the medial side of the left calf along the great saphenous vein, with the calf slightly swollen. Duplex ultrasound excluded deep vein thrombosis and found a small cyst recurrence on 
the popliteal artery. The cyst size was $12 \times 3 \mathrm{~mm}$; the lumen of the artery was not stenosed. This was most likely a clinically less-pronounced superficial phlebitis. When treated accordingly, the symptoms disappeared within a week. The most recent duplex ultrasound examination showed a residual cyst of $10 \times 2 \mathrm{~mm}$. Throughout the entire observation period, all the lower limb pulses were palpable in the patient.

Case 3. A 77 year old man presented with one-day history of an abrupt onset of intermittent claudication in the left calf after walking approximately 30 metres on flat terrain. The recovery time after the cessation of walking was 1-5 minutes. He had experienced no intermittent claudication before. He had worked as a farmer, was a non-smoker, had suffered no significant trauma

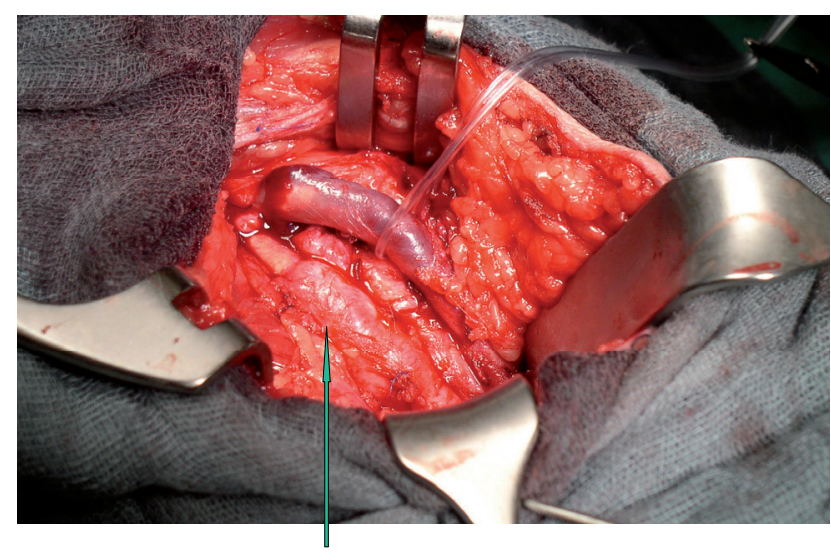

adventitial cyst

Fig. 13. Case 3: Peroperative view - popliteal artery with advetitial cyst, popliteal vein is pulled away with a tape.

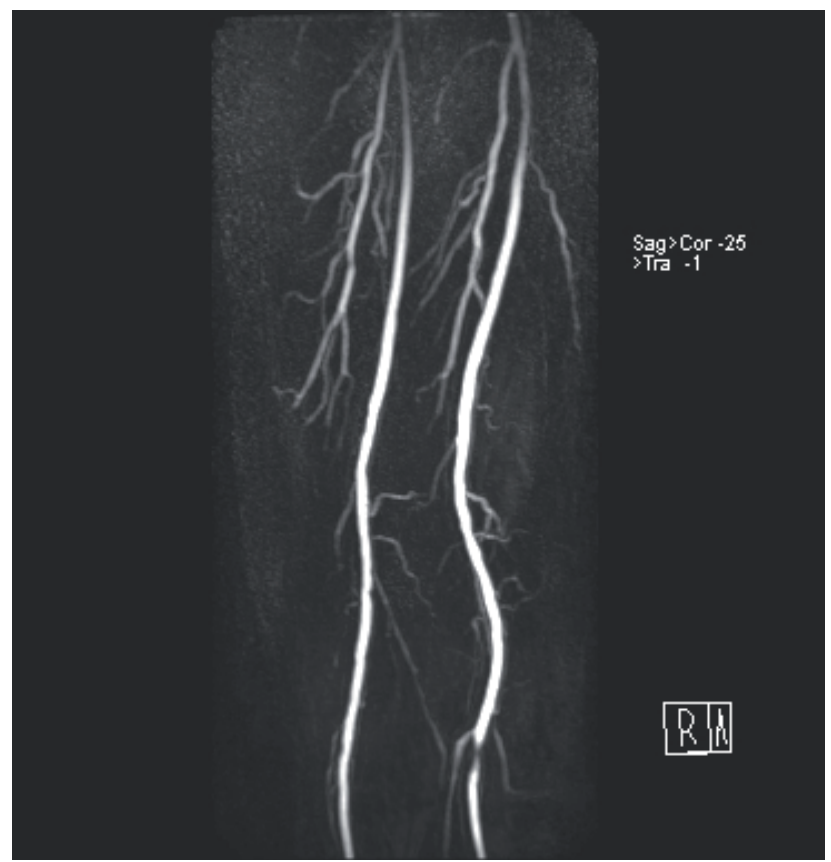

Fig. 11. Case 3: Magnetic resonance angiography scimitar sign.

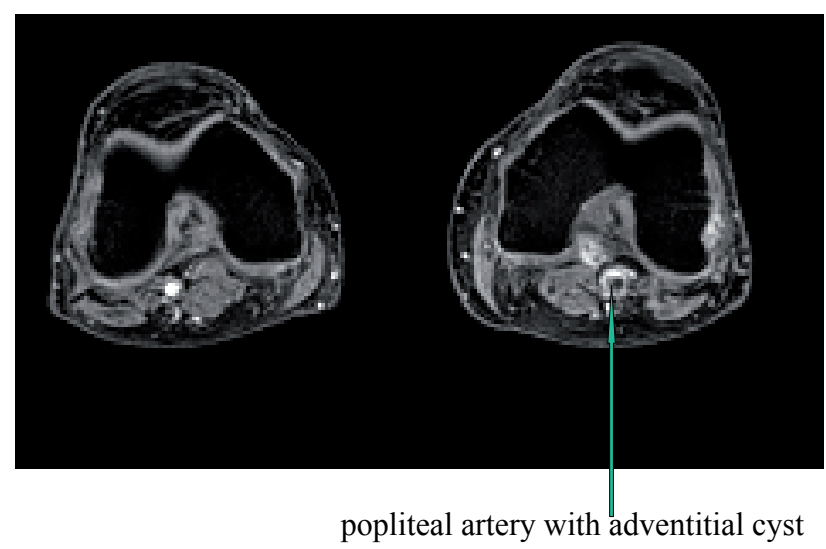

Fig. 12. Case 3: Magnetic resonance angiography, transversal scan - popliteal artery with advetitial cyst.

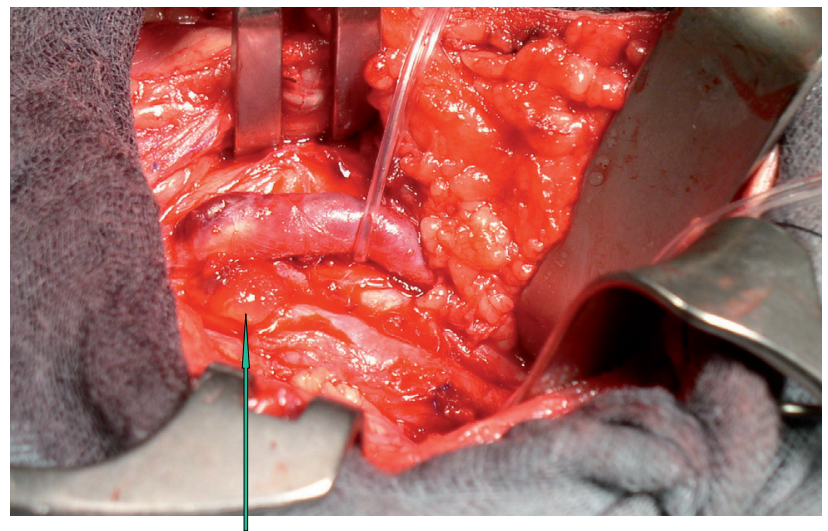

gelatinous content

Fig. 14. Case 3: Peroperative view - gelatinous content escaping from the adventitial cyst of popliteal artery, popliteal vein is pulled away with a tape.

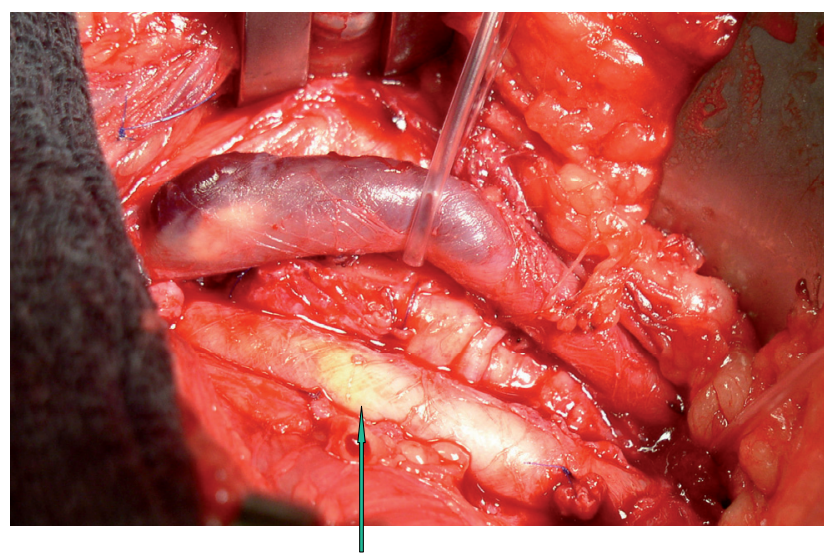

arterial wall without adventitia

Fig. 15. Case 3: Peroperative view - popliteal artery after removing of adventitia, popliteal vein is pulled away with a tape. 


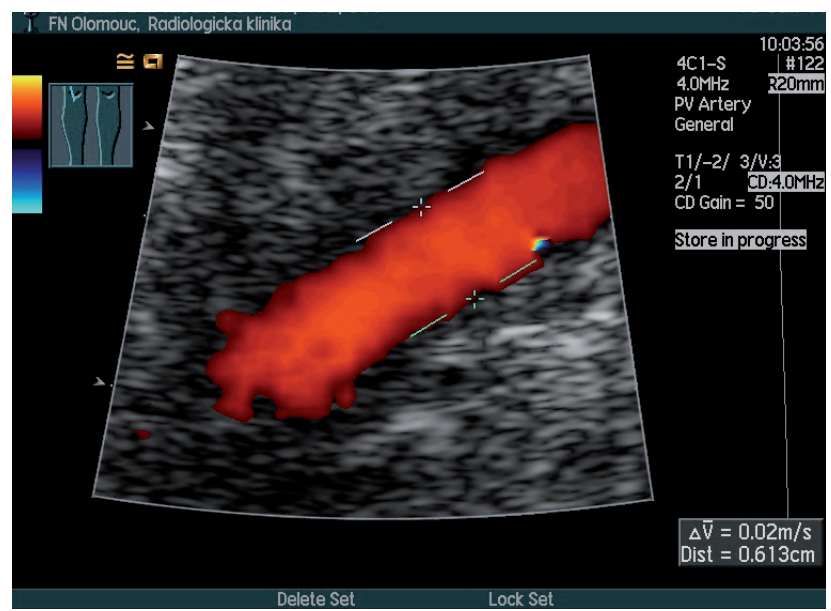

Fig. 16. Case 3: Postoperative duplex ultrasound - status after evacuation with the removal of the cystic wall - no signs of CAD recurrence, stenosis or dilatation.

and performed no extreme sports. He had undergone an urgent PCI with stent implantation for acute myocardial infarction nine months previously. Antiplatelet therapy, in this case dual one - aspirin in a dose of $100 \mathrm{mg}$ daily and clopidogrel in a dose of $75 \mathrm{mg}$ daily - had therefore already been introduced. He had been treated for mantle cell lymphoma for five years. Physical examination disclosed normal bilateral femoral and right pedal pulses, but the left pedal pulse was not palpable. There was no evidence of acute ischemia. Also in this case, the radiologist performing the duplex ultrasound examination in another medical centre suggested popliteal artery aneurysm. MRA confirmed a smooth-contoured scimitar-shaped highgrade stenosis and a cyst $15 \mathrm{~mm}$ in length and $10 \mathrm{~mm}$ in diameter in the middle segment of the left popliteal artery. No other significant atherosclerotic changes were found in the lower limb arteries. Surgery was performed through the posterior approach using an S-shaped incision, and revealed the cystic enlargement on the laterodorsal aspect of the popliteal artery. Fibrosis around the artery made the dissection difficult. No connection between the cyst and the knee joint could be found. On incision, clear gelatinous material escaped under tension from the cyst. The affected adventitial layer was resected around the entire vessel wall in the length of approximately $10 \mathrm{~cm}$. Good pulse on the popliteal artery and on the periphery of the limb was observed. No intraoperative angiogram was done. The postoperative recovery was uneventful and the patient was discharged 11 days after the surgery. In the resected adventitia, the pathologist described only fibromuscular tissue. No epithelial cells were observed in the specimen. Six months after the surgery the patient was symptom-free and the pulse to the periphery of the limb was found to be preserved. Duplex ultrasound showed no sign of recurrence or stenosis or dilatation on the left popliteal artery.

\section{LITERATURE REVIEW AND DISCUSSION}

\section{Etiology of CAD}

The etiology of CAD remains unclear. Four hypotheses have been proposed: developmental, ganglionic, microtraumatic, and degenerative, with the developmental hypothesis currently being most widely accepted.

The developmental explanation proposes that rests of undifferentiated mesenchymal cells destinated to form the joint are included in the adventitia of the adjacent blood vessel during its development. These cell rests will secrete mucoid material later in life, from which the adventitial cysts will originate. The ganglionic hypothesis presumes that adventitial cysts are ectopic synovial ganglions which migrated along the vascular branches from an adjacent joint capsule or tendon sheath into the adventitia. The microtraumatic theory is based on the repetitive trauma to vessels, which are stretched or distorted during the movement of the adjacent joints. It presumes that small detachments of the adventitia from the media cause intramural bleeding, resulting in the cystic formation by chemical enzymatic activity within the adventitia. The degenerative theory explains CAD as a myxomatous systemic degenerative condition associated with a generalized disorder ${ }^{29}$ but it has failed to gain substantial support since follow-up has shown no systemic manifestation of CAD in any patient ${ }^{15}$.

CAD occurs only in large arteries or veins which overlie a joint ${ }^{30}$. This fact was important for postulating the first three theories. Moreover, the developmental and ganglionic concepts presume a joint-related origin of adventitial cysts and are supported by other findings: A communication between adventitial cyst(s) and an adjacent joint capsule was observed during surgery by some authors ${ }^{5,8,11,22,31-34}$.The preoperative revelation of such a communication is also possible. A case of arthroscopic detection $^{35}$ and cases of MRA detection ${ }^{31,36}$ have been documented.

Some reports describe the involvement of the genicular branches in the CAD of the popliteal artery, suggesting a possible way for ganglions - synovial cysts to track along to involve the popliteal artery adventitia or as a consequence of embryonic cell migration ${ }^{28,37}$. At the biochemical level, the absence of Ulex europeus 1 reactivity of the endothelium-like cells of the lining of adventitial cysts suggests a non-vascular origin because these histochemical markers are present in the vascularly derived endothelium ${ }^{38}$.

The ganglionic theory itself is supported by the findings of Patel and Cormier ${ }^{39}$, who described a tendinous ganglion on the posterior surface of the knee in addition to popliteal artery CAD but not the communication between these lesions. Similarly, Backstrom et al. ${ }^{40}$ found the CAD of the radial artery during surgery of the recurrent ganglion of the wrist.

Schroe et al. ${ }^{41}$ even found a case in which the popliteal adventitial cyst was connected to a Baker's cyst. The patient suffered from severe ischemia only after heavy exercise, because the content of the Baker's cyst shifted into the popliteal artery cyst when the Baker's cyst was compressed. Olcott et al. ${ }^{42}$ reported a unique case with 
a clinical course typical for CAD - fluctuation in the severity of symptoms - but it was due to the intermittent compression of the artery by a Baker's cyst. This cyst was totally extrinsic and histological examination failed to reveal any cyst within the wall of the resected artery. The authors believe this lesion may be one point in the spectrum of popliteal artery CAD ( ref. $^{42}$ ). Similarly, our case no. 2 also involved the finding of an asymptomatic Baker's cyst, which was, however, observed on the other limb than that which showed popliteal artery CAD.

The macroscopic and histological appearance of the ganglion and CAD suggest that they might be of a similar origin ${ }^{43,45,47,49}$. Certain biochemical similarities have been found e.g. a rich content of hyaluronic acid and a positive alcian blue stain response of the cystic content ${ }^{38}$. However, the biochemical composition is otherwise significantly different, and studies of the chemical analyses of the fluid contents and the histochemistry of the cyst lining have therefore not provided compelling evidence in support of this theory ${ }^{43,46}$.

The developmental theory is currently the most widely accepted one. It is supported by the study by Levien and Benn $^{47}$, who drew attention to the embryologic origin of the CAD affected blood vessels and concluded that all of them were non-axial. The occurrence in the axillary artery CAD is not evidence against this theory because the axillary artery forms from a fusion of the limb bud axial artery and the six arch artery, permitting cell rests to gain access to the developing vesse ${ }^{48}$. Also the higher hyaluronic acid concentration in the adventitial cyst fluid compared to that in the synovial fluid suggests developmental aberration rather than the concept according to which the cysts are formed and maintained by communication with a synovial space ${ }^{49}$. On the other hand, the histochemical markers for synovium are absent in adventitial cysts ${ }^{38,44}$.

The microtraumatic theory was postulated on the basis of cases of popliteal artery CAD in young adults employed in heavy physical labour ${ }^{50}$, and in patients engaged in extreme sports and vigorous exercise ${ }^{25-28}$. In other patients, a definite traumatic event preceding the disclosure of CAD was identified such as falling from a bus ${ }^{51}$, pedal cycle accident $^{52}$ and repeated kneeling ${ }^{53}$. A history of heavy manual labour can be found in our second and third cases, the former of which also involves active sports. However, the history of a recurrent trauma is lacking in most published CAD cases and, on the contrary, there is a low occurrence rate of the condition among labourers and athletes, who presumably sustain far greater mechanical stress to their popliteal vessels than the general population ${ }^{54}$.

\section{Diagnostics of CAD}

The diagnostics were based on the medical history and imaging examinations; in the case of surgery, the diagnosis is confirmed peroperatively and by pathological assessment. In physical examination, in patients with CAD causing popliteal artery stenosis but not total occlusion, Ishikawa observed the loss of pedal pulses in sharp knee flexion or after exercise, which was called after him the "Ishikawa sign" (ref. ${ }^{55}$ ). Findings from the palpation of pulses are not otherwise specific for CAD, pedal pulses can be normal ${ }^{16,56}$, decreased ${ }^{28,57}$ or lost ${ }^{58}$, depending on the degree of stenosis or the presence of occlusion. In all our three reported patients, Ishikawa's test was not included in the physical examination because we did not know it at the time. Nevertheless, we expected that the diagnosis would be obtained by imaging techniques.

The typical clinical manifestation is the sudden onset of intermittent calf claudication, usually with a rapid progression. Sometimes it occurs after intense physical activity. Other previously reported characteristic features include fluctuation in the severity of the symptoms ${ }^{59-61}$. Cases of longer recovery time after cessation of exercise compared to typical claudicants and atypical symptoms suggesting a musculoskeletal rather than a vascular disorder have also been described ${ }^{16,61,62}$. Longer recovery time was observed in our first patient. Rest pain or other symptoms of acute ischemia can be present in cases of total occlusion, which occur in approximately 30 per cent of the patients ${ }^{17}$.

Severe claudication may suddenly spontaneously improve or even completely disappear and recur from a few days up to several months later ${ }^{44,59}$. The reported waxing and waning of the symptoms is explained by the fact that the amount of fluid in the cyst and the compression of the artery may vary ${ }^{63}$. Direct communication between the cyst and the knee joint is often demonstrated ${ }^{64}$, so temporary or even permanent relief from the symptoms can be explained by the drainage of the cyst content into the adjacent joint. Rupture is another possible mechanism of spontaneous CAD resolution ${ }^{5,8,11,15,16,22,31,32,35,41,59}$. In our second case, we observed changes in the size of the adventitial cyst despite constant problems perceived by the patient. Rupture of one cyst into another whose rapid growth leads to the encroachment of the arterial lumen may also be the explanation of a sudden onset of the symptoms of CAD (ref. ${ }^{23}$ ).

The patients with popliteal artery CAD who needed to rest for 10 or $20 \mathrm{~min}$ before the pain in the calf started to subside represent the above-mentioned cases of prolonged post-exercise recovery time ${ }^{35,61}$. The pressure in the cyst increases during physical activity, and the long recovery time can be explained by the slow reabsorption of the viscous fluid from the cyst after the exercise ceases and by the consequent gradual improvement in the patency of the artery ${ }^{36}$. Another theory presumes that the fluid is forced into the adventitial cyst from the knee during exercise and the existence of a valve mechanism which delays back flow to the joint at rest ${ }^{35,65}$.

A less frequent type of CAD presentation is manifested as a soft-tissue mass, causing it to be confused with a popliteal cyst or a soft-tissue neoplasm ${ }^{66}$. Also in our first case, palpable resistance was found in the popliteal fossa.

Duplex ultrasound followed by MRA including transversal postcontrast scans of the popliteal regions now appear to be the best diagnostic tools ${ }^{15,16,24,56}$. They reveal an isolated finding - adventitial cyst(s) and a smoothcontoured luminal stenosis or occlusion due to the medial and intimal compression by the cysts in the otherwise healthy arteries of lower limbs. The absence of post- 
stenotic dilation is a helpful diagnostic sign ${ }^{24}$. If the cysts are concentric (the cyst encircles the arterial lumen), the luminal stenosis will appear like an hourglass. If they are eccentric or in case of occlusion, the lesion will have curvilinear scimitar appearance. The term "Scimitar sign" is derived from the shape of a curved single-adged sword of Asian origin. In the diagnostic algorithm, high-sensitivity and high-specificity duplex ultrasound ${ }^{60}$ is currently applied to great extent. The MRA of the lower extremities then confirms the diagnosis in most cases ${ }^{67}$ and excludes generalised arterial changes or pathology in other segments of the lower limb arteries, especially in the aortoiliac region, where the duplex ultrasound sensitivity is lower. In addition, it can show the involvement of genicular arteries, if present ${ }^{28}$, the relationship between the cysts and vessels or the surrounding structures ${ }^{17,54}$. In addition, it can exclude any other pathology in a differential diagnosis - the atherosclerotic disease, popliteal aneurysm, popliteal artery entrapment syndrome, popliteal, ganglion and parameniscal cysts, soft-tissue tumors. Cases of the preoperative finding of a communication between adventitial cysts and the adjacent joint on the MRA have been published ${ }^{32,37}$. However, in most of the CAD cases with revealed knee joint connection reported in the literature, the connection was too small to be revealed by imaging techniques, and it was observed only during surgery ${ }^{16}$. The identification and resection of such a communication is presumed to diminish the risk of recurrence ${ }^{28,31,36}$.

Because of its inexpensiveness and general availability, duplex ultrasound is a suitable diagnostic modality in the follow-up after surgery or after US or CT-guided percutaneous cyst aspiration. If the findings are unclear, MRA is indicated.

CTA (ref. ${ }^{17,54}$ ) is used less frequently because it provides less morphological detail than MRA and because of radiation exposure ${ }^{15,56}$. It is essential to depict the wall of the vessel itself and the anatomical structures that surround the vessels because if only the DSA findings are reviewed, the diagnosis might not be possible as the angiographic appearances may be completely normal despite the patient's symptoms ${ }^{16,59-61}$. All the above-mentioned diagnostic methods are usually performed at rest, with the extremities extended. Under these conditions, luminal stenosis may not be present. Similarly, a simple doppler image would not show changes in the blood flow in these cases. In some instances, the stenosis is visible only in images obtained during knee hyperflexion ${ }^{27}$, such as in case of the Ishikawa sign in physical examination. However, this manoeuvre can also fail as Taurino et al. ${ }^{27}$ reported a case of the popliteal artery affected with $\mathrm{CAD}$ with no luminal stenosis on MRA and no peripheral perfusion deficit on duplex ultrasound seen during knee hyperflexion. In addition, MRA failed to visualise the adventitial cyst clearly in this case, and the definite diagnosis of popliteal artery CAD came from duplex ultrasound. Only during a treadmill exercise test at peak force and during a cramp, duplex ultrasound showed an accentuated stenosis that involved the popliteal artery lumen and corresponded to an increase in cystic volume. This case report suggests that popliteal artery CAD can become symptomatic during muscle exertion when the pressure within the fluid-filled cyst increases enough to cause a haemodynamically significant luminal stenosis. Franca $\mathrm{M}$ et al. ${ }^{16}$ reported a case of even bilateral CAD of the popliteal artery in which duplex ultrasound and MRA obtained at rest depicted only adventitial cysts with no stenosis or blood flow changes in the lower extremity arteries. Their explanation is the same - CAD can cause a dynamic exercise dependent flow obstruction. This shows that if standard, at-rest duplex ultrasound or MRA reveal only an adventitial cyst (or cysts) without the stenosis or occlusion of the popliteal artery, the stenosis or occlusion can be demonstrated through examinations performed with the hyperflexion of the knee or even after physical exercise performed with the limb. In such a case, however, the diagnosis has been determined by examinations performed at rest and we therefore believe that the performance of such steps to demonstrate a stenosis or occlusion is unnecessary. We only consider them necessary in the very rare cases where the imaging techniques have failed to show an adventitial cyst at rest. (Still, flexion is only possible in the open-type MR). Even in the above-quoted Taurino's case, only MRA failed, and CAD was demonstrated at rest by ultrasound. Primary or recurrent CAD patients without the compression of the arterial lumen during an at-rest examination (or the rare cases where a cyst has not been demonstrated at rest) cannot therefore be a priori considered to be faking the symptoms because they may indeed experience the problems during exercise because of the dynamic exercise flow obstruction.

Conventional DSA used to be considered the gold standard. Even though it is commonly performed with the limbs extended, it does enable forced knee flexion. Naturally, it does not depict adventitial cysts themselves and can therefore be diagnostic only when the cysts cause the typically shaped stenosis or occlusion. It is therefore the least beneficial method of all the imaging techniques mentioned above, not to mention its invasiveness and exposure to radiation and nephrotoxic contrast agents.

To fully cover the CAD diagnostic possibilities, intravascular ultrasound investigation (IVUS) needs to be mentioned. In 1995 the first report of CAD demonstrated by this method was published ${ }^{68}$.

In our first case, pulsatile resistance in the popliteal fossa was found. The first idea coming to the mind of each physician who at least marginally deals with vascular issues will certainly be a popliteal artery aneurysm. This may also have affected the physician performing the duplex ultrasound investigation, who described a small popliteal artery aneurysm with a wall thrombus. Our two other patients were also misdiagnosed in the same way using the same imaging method. It is therefore obvious that the low incidence of CAD in practice results in this diagnosis being left aside, and any dilation of the popliteal artery is immediately and a priori considered an aneurysm. The absence of arterial flow in the "dilated part of the artery" is then incorrectly seen as a wall thrombus. In the case of our second patient, who was treated with USguided aspiration, all the dopplerometric investigations were performed by a single experienced sonographist in 
order to ensure that the changes in the size of the cyst in time are assessed correctly. It is possible that in our first case we would have been able to obtain the diagnosis through duplex ultrasound and DSA during knee hyperflexion and using duplex ultrasound after an exercise but we did not know these diagnostic tests at the time.

\section{Treatment of $C A D$}

There are several treatment modalities. They can be divided into non-resectional and resectional ones. Nevertheless, evacuation with the removal of the cystic wall and resection with vein graft interposition are the most popular ones. CAD leading to stenoses has been solved by non-resectional techniques. Resection has been principally used in case of the complete occlusion of the popliteal artery or in case of the degeneration of the medial layer of the arterial wall. A complete list of these procedures is presented here but some of them are no longer in use because of poor results - patch angioplasties, intraoperative cyst aspiration, PTA - or are used only rarely because the anatomical circumstances are seldom suitable for them - end-to-end anastomosis, homograft. The group of non-resectional procedures consists of both surgical techniques - open cyst evacuation with the removal of the cystic wall, whether separately or with a vein patch or synthetic patch angioplasty, intraoperative cyst aspiration and those associated with interventional radiology - percutaneous ultrasound-guided or CT-guided aspiration, PTA, and exceptionally preoperative thrombolytic therapy. Tsolakis ${ }^{24}$ also includes spontaneous cyst resolution in this group. The resectional techniques involve the resection of the affected vessel and its replacement by a vein, synthetic graft or homograft, and end-to-end anastomosis.

It must be said that the technique of stand-alone open cyst evacuation with the removal of the cystic wall can vary. Indeed, some authors add that after the cyst incision and evacuation of its content the adventitia was repaired. Setacci et al. ${ }^{69}$ and Cassar et al. ${ }^{61}$ did not specify how their exact procedure but Ypsilantis et al. ${ }^{28}$ used bovine serum albumin or glutaraldehyde glue to seal the incised adventitia. Another modification of the open cyst evacuation with the removal of the cystic wall refers to extended adventitial resection called the "circumferential removal of the adventitia". This was the method preferred by Stierli et al. ${ }^{70}$. Any type of surgery should also be complemented by the identification of any communication between the affected artery and the joint, and the communication needs to be resected or ligated in order to reduce the risk of recurrence ${ }^{28,31,36}$. Similarly, the finding of an extended affected condition of the branches of the vessel, specifically of the genicular branches being affected by cysts in the case of popliteal CAD (ref. ${ }^{28,38}$ ) is considered a possible predictor of a higher risk of recurrence. However, the reports do not provide a recommendation regarding the resection of these branches.

Because of the rarity of the condition, the vast majority of the authors have had personal experience with one to three cases at maximum. Therefore, the evaluation of the results of the individual treatment modalities cannot come from one vascular centre. For that reason, efforts have been made to collect information about the individual cases reported by other authors all over the world. These authors documented the initial success rate (primary procedure), sometimes also the overall success rate (including reoperations, regardless of whether or not the given treatment modality was used to repair the previous failure of that or of another modality) in patients followed up for months to several years. However, the data were insufficient for the evaluation of the long term outcomes (e.g. 5-year patency rate of reconstructed arteries commonly documented in by-passes made for chronic lower extremity ischemia due to atherosclerosis). Although some authors did report satisfactory long-term (up to 30 years) results of both the resectional and non-resectional approaches ${ }^{6,33,71}$, they concerned experience with single cases. No large multi-centre trials exist to show the superiority of any of the treatment techniques ${ }^{72}$.

We have obtained the following information from the available literature: Flanigan and $a .^{23}$ were the first in 1979 to process and report the results obtained from correspondence with surgeons reporting this condition worldwide. They collected 98 cases from 1953 to 1977 with the adequate documentation. Later, Ishikawa ${ }^{73}$ extended the group of the Flanigan cases by adding new patients from the literature published worldwide. To our knowledge, the most recent effort of this nature was Tsolakis and al. ${ }^{24}$, who combined the data of Flanigan with 58 previously unreported cases. Ishikawa's data were also included when the appropriate outcomes were noted. In total, he evaluated the therapy of 157 cases. The publication by Asciutto et al. ${ }^{15}$ is apparently the most recent one to focus on the different approaches to the treatment of popliteal artery CAD. However, it is not an evaluation of a new patient group but rather the presentation of the outcomes reported by other authors, together with the authors' own view of the issue, where applicable. This is the approach adopted by all the other authors including us.

In both sets, i.e. Flanigan et al. ${ }^{23}$ and Tsolakis et al. ${ }^{24}$, there is a great similarity in terms of the ratio of the individual cases as far as the cases and the treatment results are concerned.

Non-resectional procedures were performed in most of the cases, with stand-alone cyst evacuation with the removal of the cystic wall accounting for a large proportion. In the resectional group, most of the cases involved vein grafts interposition, with synthetic grafts being less common. Other treatment modalities are represented by few cases in the two groups.

The mean follow-up was published by Flanigan at al. and was 20 months in the non-resectional and 33 months in the resectional group, respectively. Both authors evaluated the initial success of the individual techniques. Since the group covered by Tsolakis et al. ${ }^{24}$ included Flanigan's group plus an additional group equal in size to approximately one-third of Flanigan's group, we present Tsolakis' results here together with other reported cases. Evacuation with the removal of the cystic wall is the optimal non-resectional treatment, with the initial success rate of 94 per cent (the failure was due to CAD 
recurrence). Venous patch or synthetic patch angioplasties should be avoided because of their initial success of only 66 and 75 per cent, respectively, with the vein patch failure being mainly due to patch aneurysm development. Intraoperative cyst aspiration has a similarly low success rate, probably due to cyst recurrence. The one included case of PTA failure in popliteal artery CAD treatment represents 0 per cent in initial success ${ }^{74}$. Another case revealed the failure of this technique, too ${ }^{75}$. The likely explanation of its ineffectiveness is that the stenosis is extrinsic in nature ${ }^{17}$. Similarly, a reported case of stenting for popliteal artery stenosis due to CAD failed as, despite technical success, stent thrombosis occurred after only a week $^{76}$. A case of successful PTA of CAD in the popliteal artery that recurred after cyst evacuation with the removal of the cystic wall was reported surprisingly recently ${ }^{77}$, and a bare stent was used successfully for a short recurrence after the same procedure ${ }^{69}$.

On the contrary, in the three included cases of spontaneous cyst resolution, recurrence was not observed during follow-up, leading to the success rate of 100 per cent ${ }^{78-80}$. Other such cases involving remission during follow-up were also reported ${ }^{81}$, even after 10 years recurrence was excluded in a symptom-free patient, so the authors called this case a spontaneous and permanent CAD resolution ${ }^{72}$.

The possible mechanisms of spontaneous cyst resolution may include cyst rupture ${ }^{16,59}$ or drainage into the joint space, which is supported by the arthroscopic ${ }^{35}$, intraoperative $^{5,8,11,22,31-33,41}$ or MRA (ref. ${ }^{32,37}$ ) findings of a direct communication between the popliteal artery adventitial cyst and the knee joint. Despite the above-mentioned excellent results Holden et al. ${ }^{59}$ and Asciutto et al. ${ }^{15}$ emphasise that the relief is frequently only temporary, with the recurrence of the cysts and symptoms after a period ranging from a few days to several months.

The total occlusion of the popliteal artery can be either due to the contact between the intimal surfaces of the vessel without thrombosis or a thrombus may superimpose the stenosis. The former was demonstrated by Milliken $^{82}$ who performed cyst evacuation with the removal of the cystic wall for a total occlusion. After the evacuation of the cyst content he completed arteriotomy by incision in the medial and intimal layers and found no evidence of thrombotic occlusion. He passed a Fogarty catheter upwards and downwards along the popliteal artery in order to ensure that a thrombus had not been overlooked. However, reocclusion occurred within one year, which supports the opinion of resectional technique preference in case of a complete occlusion. The latter possibility, thrombus formation related to popliteal artery CAD, was proved by Samson et al. ${ }^{83}$ Using local urokinase lytic therapy, they achieved the complete resolution of the clot in the popliteal artery but scimitar sign stenosis appeared upon angiography. Cyst evacuation with the removal of the cystic wall followed. At 6-months follow-up, the patient remained asymptomatic and duplex Doppler examination showed normal findings. This case is also an example of a successful thrombus lyse, thus allowing the non-resectional treatment of a complete occlusion. However, with regard to the possibility of occlusion with- out thrombosis, it is clear that this procedure can not be successful in all cases.

Resection followed by vein graft interposition had initial success in 95 per cent of the cases, with the failure being due to graft thrombosis. However, failure due to CAD recurrence in an interposed vein graft is also possible, as described by Ohta et al. ${ }^{84}$ at 6 months after the procedure. Resection and interposition synthetic grafting led to the initial success of $90 \%$, with failure being due to thrombosis. Again, however, CAD can recur in this type of replacement, as Patel et al. ${ }^{85}$ reported in their 18-months follow up. The reason for these recurring findings is unclear, but incomplete cyst excision is possible ${ }^{24}$. Three cases of end-to-end anastomosis and two cases of homograft replacement resulted in 100 per cent initial success. In addition, Flanigan ${ }^{23}$ also reported the overall success of individual procedures which did not significantly differ from the initial success: only the occlusion of one dacron prosthesis which was used for thrombosed vein graft replacement worsened the synthetic graft patency by 11 per cent, otherwise the maximum difference was 5 per cent. The good results of the most frequently used techniques, i.e. evacuation with the removal of the cystic wall, and resection followed by vein graft or synthetic graft replacement (initial success of 90 per cent and more in all these techniques), are probably associated with the fact that CAD causes an isolated finding, with the inflow and outflow tract intact ${ }^{23}$. Most surgeons continue to suggest the above-mentioned principle - they prefer cyst evacuation with the cystic wall removal for CAD with a patent popliteal artery and graft interposition for the occlusion or if the media is involved ${ }^{24,33}$, $45,59,61,82$. The good results were achieved regardless of the type of grafting ${ }^{15,24}$. Thus the material of choice has often been an autologous vein ${ }^{15,23,24}$ which has the advantage of being free of charge (but includes the necessity of harvesting on the other hand) and probably also because it has marked slightly better results in comparison with a prosthetic graft as mentioned above. In addition, if the lesser saphenous vein is of a suitable calibre and quality, the entire procedure can be done through a posterior S-shaped approach ${ }^{15,24}$. This approach is commonly used. Nevertheless, the medial approach involving the transection of the medial gastrocnemius head is also possible ${ }^{70}$.

Even though there is no significant difference between the resectional a non-resectional groups based on the previously reported treatment outcomes ${ }^{24,69}$ some surgeons prefer the first or the second treatment modality. The promoters of evacuation with the removal of the cystic wall emphasise the advantage of native medial and intimal layers preservation and the absence of dilatation of the popliteal artery even after extended adventitial resection. In addition, they refer to the well-known disadvantages of vein grafts such as the development of intimal hyperplasia with anastomotic stenosis or of graft thrombosis, and occasional aneurysmal dilatation over several years ${ }^{81}$. Surgeons preferring reconstruction with an autologous vein graft refer, above all, to the high risk of recurrence when the evacuation and excision of the cyst are used, which was reported in approximately $10 \%$ of the cases 
after this procedure ${ }^{6,23}$. The outcome concerning CAD recurrence is better after graft interposition ${ }^{6}$, but the failure of this method is also possible, as mentioned above ${ }^{84,85}$.

In order to reduce recurrence after evacuation with the removal of the cystic wall, Stierli et al. ${ }^{70}$ use the so-called "circumferential removal" of the adventitia. Although the adventitial cysts are often located asymmetrically, they authors report that resecting the adventitial layer along its full length circumferentially around the entire vessel wall prevents small cysts from giving rise to recurrence. The outermost layer of the media is also resected and can be entered without problems. Six patients with popliteal artery CAD were included in this long-term follow-up study. The authors did not know if such extended resection would alter the stability of the arterial wall or if it would lead to stenotic scar formation, but there were no signs of recurrent $\mathrm{CAD}$, stenosis or dilatation of the popliteal artery after the follow-up of between 2 and 10.5 years. We removed the adventitia around the entire vessel wall in our case no. 3. Six months after the surgery the patient is symptom-free with the preserved pulse to the periphery of the limb. Duplex ultrasound shows no sign of recurrence, stenosis or dilatation of the operated popliteal artery.

The latest method in popliteal artery CAD management is US or CT - guided percutaneous cyst aspiration. Only several cases have been reported so far, and with different outcomes. In 1985, this method was reported as successful and simple ${ }^{86}$ but later aspiration was not possible in one documented case because the content was too viscous ${ }^{87}$, and early recurrence was documented in another case ${ }^{88}$. This technique has been therefore considered unsuccessful because of the frequent recurrence ${ }^{17,25,59,61,89}$ resulting from the multilocularity, high viscosity of the gelatinous material which is difficult to aspirate, and because of the reaccumulation of the cystic content. This is not surprising according to Cassar and Engeset ${ }^{61}$, considering the fact that many of these cysts communicate with the adjacent joint and that aspiration will not therefore obliterate the communication. Also in our second case, this method was used a total of four times because of the cyst recurrence but, on the other hand, the patient has needed no intervention in the past four and half years. A $16-\mathrm{G}$ needle has proved most suitable for the aspiration of the viscous material. A case of the excellent outcome of US-guided percutaneous cyst aspiration has recently been reported in which negative findings in the treated popliteal artery in a completely asymptomatic patient were documented even 11 years after the procedure ${ }^{63}$. Even though many more cases are needed to establish the role of this method in CAD treatment, its advantages are beyond question: it is a minimally invasive method which can be performed as an outpatient procedure, it can be offered to patients refusing surgery, and it does not prevent surgery in the future, if needed ${ }^{15,63}$.

In conclusion, the current knowledge of CAD management shows that surgery (either evacuation with the removal of the cystic wall or, potentially, its variant - the circumferential removal of the adventitia or resection with vein grafting) appears to be the best treatment. Because of the rare nature of $\mathrm{CAD}$, it is a question whether the conditions will be optimal in the future for organising a multi-centre trial in order to demonstrate which treatment modality is the best.

\section{CONCLUSION}

CAD of the popliteal artery is a rare vascular condition but it must be considered in the differential diagnosis, in particular for middle-aged male patients who show no evidence of the atherosclerotic disease and in whom claudication has suddenly developed, especially after a vigorous activity, in whom the symptoms fluctuate in severity, and who show longer recovery times. In the diagnostic algorithm, duplex ultrasound should by performed first to reveal the diagnosis; subsequent MRA should be preferred to CTA or DSA to confirm the condition. Nevertheless, the low incidence of CAD in practice results in this diagnosis being left aside, and any dilation of the popliteal artery diagnosed by duplex ultrasound is often considered an aneurysm.

Based on the existing knowledge, surgery is the treatment of choice (either evacuation with the removal of the cystic wall or resection and vein grafting). As far as the first treatment modality, its variant called "the circumferential removal of the adventitia" should be considered, based on good outcomes. The communication with the knee joint, if any, should be surgically treated. The same may apply to the potential involvement of the genicular branches.

The outcomes of US - and CT-guided percutaneous cyst aspiration remain ambiguous. Long-term or even lifelong follow-up is recommended in order to reveal and treat any recurrence.

\section{ABBREVIATIONS}

CAD, Cystic adventitial disease; CTA, Computer tomography angiography; CT-guided aspiration, Computer tomography guided aspiration; DSA, Digital subtraction angiography; ePTFE, Expanded polytetrafluorethylene; MR, Magnetic resonance; MRA, Magnetic resonance angiography; PCI, Percutaneous coronary intervention; PTA, Percutaneous transluminal angioplasty; US-guided aspiration, Ultrasound-guided aspiration

\section{REFERENCES}

1. Andersson T, Gothman B, Lindberg K. Mucinous cystic dissecting intramural degeneration of the popliteal artery. Acta Radiol 1959;52:455.

2. Wali MA, Dewan M, Renno WM, Ezzeddin M. Mucoid degeneration of the brachial artery: case report and a review of literature. J R Coll Surg Edinb 1999;44:126-9.

3. Atkins H, Kay J. A case of myxomatous tumor arising in the adventitia of the left external iliac artery Br J Surg 1647;34:426-7.

4. Heim C, Rosso R. Zystische Adventitiadegeneration der Arteria iliaca externa - ein Fallbericht mit Langzeitverlauf. Swiss Surg 2001;7,90-4. 
5. Campbell WB, Millar AW. Cystic adventitial disease of the common femoral artery communicating with the hip joint. Br J Surg 1985;72:537.

6. di Marzo L, Peetz DJ Jr, Bewtra C, Schultz RD, Feldhaus RJ, Anthone G. Cystic adventitial degeneration of the femoral artery: is evacuation and cyst excision worthwhile as a definitive therapy? Surgery 1987; 101:587-93.

7. Gagnon J, Doyle DL. Adventitial cystic disease of common femoral artery Ann Vasc Surg 2007;21,84-6.

8. Hall RI, Proud G, Chamberlain J, McNeil IF. Cystic adventitial disease of the common femoral and popliteal arteries. Br J Surg 1985;72:756-8

9. Elster EA, Hewlett S, DeRienzo DP, Donovan S, Georgia J, Yavorski CC. Adventitial cystic disease of the axillary artery. Ann Vasc Surg 2002;16:134-7.

10. Parkes A. Intraneural ganglion of the lateral popliteal nerve. Journal of Bone and Joint Surgery 1961;43B:784.

11. Wang H, Spinner RJ, Amrami KK. Adventitial cyst of the radial artery with a wrist joint connection. Journal of Hand Surgery 2007;32:126-30

12. Chakfé N, Beaufigeau M, Geny B, Suret-Canale MA, Vix J, Groos N, Edah-Tally S, Steinmetz E, Kretz JG. Extra-popliteal localizations of adventitial cysts. Review of the literature J Mal Vasc 1997;22:79-85.

13. Dix FP, McDonald M, Obomighie J, Chalmers N, Thompson D, Benbow EW, Smyth JV. Cystic adventitial disease of the femora vein presenting as deep vein thrombosis: a case report and review of the literature. J Vasc Surg 2006;4:871-4.

14. Chbani L, Lepreux S, Casoli V, Bioulac-Sage P. Kyste adventitie veineux: 'a propos d'un cas Venous cystic adventitial disease: A case report. Annales de Pathologie 2008;28: 498-500.

15. Asciutto G, Mumme A, Marpe B, Hummel T, Geier B. Different approaches in the treatment of cystic adventitial disease of the popliteal artery. Chir Ital 2007;59:467-73.

16. Franca M, Pinto J, Machado R, Fernandez GC. Case 157: Bilateral adventitial cystic disease of the popliteal artery Radiology 2010;255:655-60.

17. Ortiz MW, Lopera JE, Giménez CR, Restrepo S, Moncada R, Castaneda-Zuniga WR. Bilateral adventitial cystic disease of the popliteal artery: a case report. Cardiovasc Intervent Radiol 2006;29:306-10.

18. Ishibashi S, Namiki K, Abe M, Shirata Y, Ohnishi K, Toyoda T, Ohuchi K.Cystic adventitial disease of the popliteal artery - a case of young boy. Tohoku J Exp Med 1995;176, 173-80.

19. Harris JD, Jepson RP. Cystic degeneration of the popliteal artery. Austr N J J Surg 1965;34:265.

20. Lewis GJT, Douglas DM, Reid W, Kennnedy-Watts J. Cystic adventitial disease of the popliteal artery. Br Med J 1967;3:411.

21. Zinicola N, Ferrero S, Odero A. Adventitial cyst of the popliteal artery. Case report. Minerva Cardioangiol 1973;21,474.

22. Seitz CJ. Adventitial cystic disease of the popliteal artery: a clinical case. Angiologia 1991;126:128-9.

23. Flanigan DP, Burnham SJ, Googreau, JJ, Bergan JJ. Summary of cases of adventitial cystic disease of the popliteal artery Ann Surg 1979; $189: 165-75$

24. Tsolakis IA, Walvante CS, Caldwell MD. Cystic adventitial disease of the popliteal artery: diagnosis and treatment Eur J Vasc Endovasc Surg 1998;15:188-94.

25. Sys J, Michielesen J, Bleyn J. Adventitial disease of the popliteal artery in a triathlete: a case report Am J Sports Med 1997;25:854-7.

26. Wolk, SW, Lampman, RM, Misare, BD, Erlandson EE, Whitehouse WM. Popliteal artery occlusion secondary to cystic adventitial disease: A rare etiology of lower extremity ischemia in a marathon runner: A Case report. J Vasc Surg 1998;32:623-6.

27. Taurino M, Rizzo L, Stella N, Mastroddi M, Conteduca F, Maggiore C, Faraglia V. Doppler ultrasonography and exercise testing in diagnosing a popliteal artery adventitial cyst Cardiovascular Ultrasound 2009;7:23.

28. Ypsilantis EA, Tisi PV. Involvement of the genicular branches in cystic adventitial disease of the popliteal artery as a possible marker of unfavourable early clinical outcome: a case report. Journal of medical case reports 2010;4:91.
29. Linquette M, Mesmacque R, Beghin B, Hubschman B, Soots G. Degenerescence kystique de l' adventitie de l'artere popliitee. Semaine Hop Paris 1967;43:3005-13.

30. Jasinski RW, Masselink BA, Partridge RW, Deckinga BG, Bradford PF. Adventitial cystic disease of the popliteal artery. Radiology 1987; 163,153-5.

31. Unno N, Kaneko H, Uchiyama T, Yakamoto N, Nakamura S Cystic adventitial disease of the popliteal artery: elongation into the media of the popliteal artery and communication with the knee joint capsule - report of a case. Surg Today 2000;30:1026-29.

32. Ortmann J, Widmer MK, Gretener S, Do DD, Willenberg T, Dalir A, Baumgartner I. Cystic adventitial degeneration: ectopic ganglia from adjacent joint capsules. Vasa 2009;38:374-7.

33. Melliere D, Ecollan P, Kassab M, Becqemin JP. Adventitial cystic disease of the popliteal artery: treatment by cyst removal. J Vasc Surg 1988;8:638-42.

34. Slyško R, Šefránek V, Dulka T, Tomka J, Mondek P, Zita Z. Cystická degeneracia adventície a. poplitea - case report Rozhl Chir 2002;81:297-300.

35. Hunt BP, Harrington MG, Goode SS, Galloway JMD. Cystic adventitial disease of the popliteal artery. Br J Surg 1980;67:811-12.

36. Maged IM, Turba UC, Housseini AM, Kern JA, Kron IL, Hagspiel KD. High spatial resolution magnetic resonance imaging of cystic adventitial disease of the popliteal artery J Vasc Surg 2010;52:5345 .

37. Crolla RM, Steyling JF, Hennipman A, Slootweg PJ, Taams A. A case of cystic adventitial disease of the popliteal artery demonstrated by magnetic resonance imaging. J Vasc Surg 1993;18:1052-5.

38. di Marzo L, Rocca CD, d'Amati G, Gallo P, Sciacca V, Mingoli A, Cavallaro A. Cystic adventitial degeneration of the popliteal artery: Lectin-histochemical study. Eur J Vasc Surg 1994;8:16.

39. Patel $\mathbf{J}$ and Cormier JM. La degenerescence kystique ou colloide de l' adventice arteriel. Presse Med 1963;71:244.

40. Backstrom CG, Linnel F and Ostberg G. Cystic myxomatous adventitial degeneration of the radial artery with development in the connective tissue. Acta Chir Scand 1965;129:447.

41. Schroe H, Van Opstal C, De Leersnijder J, De Cort J, Suy R. Baker's cyst connected to popliteal artery cyst Annals of vascular surgery 1988;4:385-9.

42. Olcott C, Mejigan VT. Popliteal artery stenosis caused by a Baker's cyst J Vasc Surg 1986;4:403-5.

43. Leaf G. Amino-acid analysis of protein present in a popliteal artery cyst Br Med J 1967;3:415.

44. Devereux D, Forrest H, McLeod T, Ahweng A. The non-arteria origin of cystic adventitial disease of the popliteal artery in two patients. Surgery 1980;88:723-7.

45. Shabbo FP. Cystic disease of the popliteal artery Am Surg 1982;69:362.

46. Endo M, Tamura S, Minakuchi S, Ouchi H, Yosizawa Z. Isolation and identification of proteohylaluronic acid from a cyst of cystic mucoid degeneratuion Clin Chim Acta 1973;47:417-24.

47. Levien LJ, Benn CA. Adventitial cystic disease: a unifying hypothesis. J Vasc Surg 1998;28:193-205.

48. Levien LJ. Chapter 86 - Nonateromatous causes of popliteal artery disease. In: Rutherford RB, editor. Vascular surgery. Philadelphia: WB Saunders; 2005. p.

49. Jay GD, Ross FL, Mason RA, Giron F. Clinical and chemical characterisation of an adventitial popliteal cyst. J Vasc Surg 1989;3:448.

50. Bliss, BP. Cystic myxomatous degeneration of the popliteal artery. Am Heart J 1964;68,:838.

51. Flanc, C. Cystic degeneration of the popliteal artery Aust NZ J Surg 1967;36:243.

52. Tytgat H, Derom F, Galinsky A. Degenerescence kystique de l'artere poplitee traitee par greffe en nylon. Acta Chir Belg 1958:57:188.

53. Holmes JG. Cystic adventitial degeneration of the popliteal artery JAMA 1960;173:654.

54. Bergan JJ. Adventitial cystic disease of the popliteal artery. In: Rutherford RB, editor. Vacular surgery. Philadelphia: WB Saunders; 1995. p. 883-8.

55. Ishikawa K, Mishima Y, Kobayashi S. Cystic adventitial disease of the popliteal artery. Angiology 1961;12:357-66 
56. Köcher M, Černá M., Utíkal P, Šišola I, Bučil J, Dráč P, Bachleda P, Horák D. Cystická degenerace adventicie arteria poplitea perkutánní léčba Čes Radiol 2006;60:134-9.

57. Tomasian A, Lai C, Finn JP, Gelabert H, Krisham MS. Cystic adventitial disease of the popliteal artery : features on 3T cardiovascular magnetic resonance J Cardiovasc Magn Reson 2008;13:38.

58. Motaganahalli RL, Pennel RC, Mantese VA, Westfall SG. (2009) Cystic adventitial disease of the popliteal artery. J Am Coll Surg 2009;209:541.

59. Holden A, Merrilees S, Mitchell N, Hill A. Magnetic resonance imaging of popliteal artery pathologies. Eur J Radiol 2008;67,:15968.

60. Brodmann M, Stark G, Pabst E, Seinost G, Schweiger W, Szolar D, Pilger E. Cystic adventitial degeneration of the popliteal artery: the diagnosis value of duplex sonography. Eur J Radiol 2001; 38:20912.

61. Cassar K, Engeset J. Cystic adventitial disease: a trap for the unwary Eur J Vasc Endovasc Surg 2005;29:93-6.

62. Wright LB, Matchett WJ, Cruz CP, James CA, Culp WC, Eidt JF, McCowan TC. Popliteal artery disease: diagnosis and treatment RG 2004;24:467-79.

63. Keo HH, Baumgartner I, Schmidli J, Do DD. Sustained remission 11 years after percutaneous ultrasound-guided aspiration for cystic adventitial degeneration in the popliteal artery. Journal of Endovascular therapy 2007;14:364-5.

64. Leu HJ, Largiader J, Odermatt B. Pathogenesis of the so-called cystic adventitial degeneration of periphearl blood vessels. Virchows Arch A Pathol Anat Histopathol 1984;404:289-300.

65. Jayson MIV, Dixon AS. Valvular mechanisms in juxta-articular cysts. Ann Rheum Dis 1970;29:415-20.

66. Peterson JJ, Kransdorf MJ, Bancroft LW, Murphey MD. Imaging characteristics of cystic adventitial disease of the peripheral arteries: presentation as soft-tissue masses. AJR Am J Roentgenol 2003; 180:621-5.

67. Rispoli, P, Moniaci D, Zan S, Cassatella R, Varetto G, Masselli M, Apostolon D, Raso AM, Conforti M. Cystic adventitial disease of the popliteal artery. Report of one case and review of the literature. J Cardiovasc Surg 2003;44:255-8

68. Koppensteiner R, Katzenchlager R, Ehringer H. Cystic adventitial disease of the popliteal artery demostrated by intravascular ultrasound imaging. Abstract. $17^{\text {th }}$ World Congress of the International Union of Angiology 14, (1995) p.1 Suppl. 1.

69. Setacci F, Sirignano P, de Donato G, Chisci E, palasciano G, Setacci C. Adventitial cystic disease of the popliteal artery: experience of a single vascular and endovascular center. 2008;49:235-9.

70. Stierli P, Mauch J, Koella C, Huber A, Eugster T, Gürke L. Circumferential removal of the adventitia for cystic degeneration of the popliteal artery British Journal of Surgery 2005;92:56-7.

71. Hierton T, Hemmingsson A. The autogenous vein graft as popliteal artery substitute. Long-term follow-up of cystic adventitial degeneration. Acta Chir Scand 1984;150:377-83.

72. Pursell R, Torrie EP, Gibson M, Galland RB. Spontaneous and permanent resolution of cystic adventitial disease of the popliteal artery. J R Soc Med 2004;97:77-8.
73. Ishikawa K. Cystic adventitial disease of the popliteal artery and of other stem vessels in the extremities Jap J Surg 1987;17,221-9.

74. Fox RL, Kahn M, Adler J, Sussman B, Mendes D, Ibrahim IM, Dardik H. Adventitial cystic disease of the popliteal artery: failure of percutanous transluminal angioplasty as a theraputic modality. J Vasc Surg 1985;2:464-7.

75. Khoury M. Failed angioplasty of a popliteal artery stenosis secondary to cystic adventitial disease: A case report. Vasc Endovasc Surg 2004;38:277-80.

76. Rai S, Davies RS, Vohra RK. Failure of endovascular stenting for popliteal cystic disease Ann Vasc Surg doi: 10.1016/j. avsg.2008.01.014 Published online May 22, 2008. Accessed January 26, 2009.

77. Maged IM, Kron IL, Hagspiel K. Recurrent cystic adventitial disease of the popliteal artery: Successful treatment with percutaneous transluminal angioplasty. Vasc Endovas Surg 2009;43:399-402.

78. Lossef SV, Rajan S, Calcagno D, Jelinge E, Patt R, Barth KH. Spontaneous rupture of an adventitial cyst of the popliteal artery: confirmation with MR imaging J Vasc Interv Radiol 1992;3:95-7.

79. Owen ERTC, Speechly-Dick EM, Kour NW, Wilkins RA, Lewis JD. Cystic adventitial disease of the popliteal artery: a case of spontaneous resolution. Eur J Vasc Surg 1990;4:319-21.

80. Furunaga A, Zempo N, Akiyama N, Takenaka H, Kuga T, Fujioka $\mathrm{K}$, Esato K. Cystic disease of right popliteal artery with spontaneous resolution. J Jap Surg Soc 1992;93:1501-3.

81. Soury P, Riviere JJ, Watelet J, Peillon C, Testart J. Spontaneous regression of a sub-adventitial cyst of the popliteal artery $\mathbf{J}$ Mal Vasc 1995;20:323-5.

82. Milliken JC. Cystic degeneration of the popliteal artery in a female. British medical journal 1971;26:769-70.

83. Samson RH, Willis PD. Popliteal artery occlusion caused by cystic adventitial disease: successful treatment by urokinase followed by non-resectional cystotomy. J Vasc Surg 1990;12:591-3.

84. Ohta T, Kato R, Sugimoto I, Kondo M. Recurrence of cystic adventitial disease in an interposed vein graft Surgery 1994;116:587-92.

85. Patel SM, Patil VA, Pomoukian VN. Interposition grafting of popliteal artery cystic adventitial disease: case report Vasc Endovascular Surg 2008;42:192-5.

86. Deutsch A, Hyde J, Miller SM, Diamond CG, Schanche AF. Cystic adventitial degeneration of the popliteal artery: CT demonstration and direcrted percutanous therapy. AJR 1985;145:117-8.

87. Wilbur AC, Spigos DG. Adventitial cyst of the popliteal artery: CT-guided percutaneous aspiration. J Computer Assist Tomogr 1986;10,161-3.

88. Sieunarine K, Lawrence-Brown MM, Kelsey P. Adventitial cystic disease of the popliteal artery: early recurrence after CT-guided percutaneous aspiration. J Cardiovasc Surg 1991;32:702-4.

89. Do DD, Braunschweig M, Baumgartner I, Furrer M, Mahler F. Adventitial cystic disease of the popliteal artery: percutaneous USguided aspiration. Radiology 1997;203:743-6 
